V.G. Kuznetsov, Yu.I. Tugay, V.V. Kuchanskiy,Yu.G. Lyhovyd, V.A. Melnichuk

\title{
THE RESONANT OVERVOLTAGE IN NON-SINUSOIDAL MODE OF MAIN ELECTRIC NETWORK
}

Purpose. The resonant overvoltage arises in main electrical networks as a result of random coincidence of some parameters of circuit and its mode and it may exist for a relatively long time. Therefore, the traditional means of limitation of short duration commutation surges are not effective in this case. The study determines conditions of appearance and development of nonsinusoidal mode after switching idle autotransformer to the overhead line of extra high voltage. The purpose of the paper is to choice measures for prevention overvoltage, too. Methodology. The study has used the result of extra high voltage line testing, the methods of electric circuit theory and the simulation in the MATLAB \& Simulink package. Results. The simulation model of the extra high voltage transmission line for the study of resonant non-sinusoidal overvoltage is developed. The conditions for the appearance of resonant circuits in the real power line are found and harmonic frequency in which overvoltage arises are obtained. The study proposes using the controlled switching device as a measure to prevent resonance surges and determines the appropriate settings. Originality. The expression for calculation of resonant length of extra high voltage line was derived. The special investigation of processes in the resonant circuit of the extra high voltage transmission line for higher harmonic components of voltage is carried out. The program of switching for control apparatus that prevents non-sinusoidal overvoltage has been developed at the first time. Practical value. The using of the proposed settings of controlled switchgear will prevent the occurrence of hazardous resonant surge on higher harmonic components of voltage. References 10, figures 4.

Key words: main electric network, extra high voltage transmission line, resonant overvoltage, nonsinusoidal mode, controlled switching.

Резонансные перенапряэсения в магистральных электрических сетях возникают вследствие случайного совпадения параметров схемы и режсма и могут существовать сравнительно длительное время. Поэтому традиционные средства для их ограничения в данном случае неэффективны. Целью статьи является исследование перенапряжений, возникающих в магистральных электрических сетях на высших гармониках. Для этого было использовано имитационное и математическое моделирование в среде MATLAB\&Simulink. Показано, что несинусоидальные искажения возникают при включении линии электропередачи на автотрансформатор в режиме холостого хода. Определень соответствующие частоты. Предложено использование устройства управляемой коммутации для предотвращения перенапряжения данного класса и разработана модель для определения соответствующих настроек. Библ. 10, рис. 4.

Ключевые слова: магистральная электрическая сеть, линия электропередачи сверхвысокого напряжения, резонансные перенапряжения, несинусоидальный режим, управляемые коммутации.

Introduction. Trends in the development of modern main electric networks indicate the growth of the role of super high voltage transmission lines (SHVTL) as both system-forming and inter-system. It should be noted that it is the study of overvoltage of this class of lines should be carried out particularly carefully, in particular, taking into account the influence of possible sources of distortion. This is due to the practical absence of an operating reserve of insulation, calculated for extreme parameter values, since such a reserve for extra high voltage has a high cost [1-4]. Experience of operation of $\mathrm{AC}$ electric networks indicates that under certain conditions in them there are stable fluctuations of currents and voltages with frequencies other than normal operating frequency. As a result, an analysis of the possibility of overvoltage in the transmission lines of the SHVTL should be performed not only for normal, but for abnormal (asymmetric and non-sinusoidal) modes.

It should also be noted that in the main electric networks of Ukraine the nominal voltage of $750 \mathrm{kV}$ the replacement of the air circuit breakers into the $\mathrm{SF}_{6}$ ones has been carried out. Compared to the air circuit breakers, $\mathrm{SF}_{6}$ ones have certain advantages, the most important of which are the high operation speed and high ability to extinguish the arc, as well as the ability to control the switching process. The objective reason for such a modernization is also that the Ukrainian electrical engineering industry does not manufacture air switches, and in the event of their damage, proper repairs and renewals of the electricity supply becomes a complicated task.

In general, the switching time point of the air circuit breaker commutation is a random variable due to its low speed, which is why it is unrealistic to perform opening and closing at the chosen particular moment. This uncertainty of the initial conditions makes the transient process unpredictable after switching, and the appearance of internal overvoltage is unexpected. During operation it is possible to develop emergency situations, including the emergence of overvoltage in non-sinusoidal modes $[2,5,6]$. The $\mathrm{SF}_{6}$ circuit breaker allows for commutation at any moment of the sinusoidal voltage change, which control device chooses according to the criterion for reducing the negative effects of transients.

The goal of the work is establishment of the conditions for the appearance and development of internal overvoltage that arises in main electrical networks on the higher harmonic components, as well as the choice of measures for their prevention. One of these measures is to perform controlled switching according to selected criteria, which allows to reduce the values of overvoltage to the level of effective operation of traditional protective devices, for example, nonlinear overvoltage limiters. To do this, intervals of switching angles of circuit the breaker 
were determined, which allows the operation to be carried out without dangerous excess of voltage levels.

Investigation of resonant overvoltage in SHVTL. The main direction of previous studies of overvoltage [2-9] using mathematical modeling was focused on the development and application of mathematical models for quantitative results in order to limit overvoltage at the main frequency. They did not consider the physical processes of the development of resonance overvoltage on even harmonic components, although the occurrence of this type of overvoltage is known for a relatively long time. Therefore, it was unclear from the results obtained that the modes or commutations themselves lead to resonant overvoltage on higher harmonics and such studies can not be considered exhaustive.

Investigation of resonant overvoltage in nonsinusoidal modes of SHVTL. A prerequisite for the emergence of resonance overvoltage at higher harmonic frequencies is the development of an abnormal non-sinusoidal mode of the SHVTL [2-7]. Typically, sources of distortion of the shape of the curve of the voltage and currents in the transmission of SHV are ferromagnetic shunts of magnetization of transformers. It should be noted that oscillatory processes in circuits with steel require special attention in investigations of modes of main electrical networks, as linear resonances on higher harmonic components, the source of which is nonlinear inductance, and nonlinear resonances, in which this inductance is part of the resonance circuit, are possible $[2,5,6]$.

A characteristic non-sinusoidal power transmission mode of the SHV is the connection of an unloaded power autotransformer (AT) to the transmission line. The physics of the process of the appearance of even harmonic components in the SHVTL with connected unloaded AT is due to the periodic change in the inductance of the magnetic shunt when the AC passes through it. This inductance varies with a double frequency in relation to the applied voltage. But it should be noted that although in theory the process of occurrence of overvoltage on even harmonic components is generally known, but the detection of factors of an abnormal mode that affect the multiplicity and duration of overvoltage of this type in practice requires additional research. It is necessary during the design and operation of main electrical networks to have means to check the possibility of not only the necessary but also sufficient conditions for the appearance of abnormal overvoltage and its possible multiplicity.

A sufficient condition for the occurrence of overvoltage on the even harmonic components is the coincidence of the parameters of the elements of the substitution circuit of the SHVTL, at which the frequency of the proper oscillations will be approximated to $100 \mathrm{~Hz}$. For this it is necessary that the input impedance of the line has a capacitive character and was approximately equal to the average value of the inductive resistance of the magnetic shunt of the autotransformer at this frequency. The condition will be fulfilled only at certain lengths of the SHVTL, which can be called resonant.

Main networks operate with a grounded neutral, therefore, at simplified analysis of the resonant power transmission properties in a symmetrical non-sinusoidal mode, an one-line substitution circuit of an equivalent two-terminal network can be used. To find the critical resonance values of the transmission line lengths, the expression in the denominator of the input impedance of the equivalent two-terminal network of the TL, to which the unloaded AT connects, is extrapolated by the polynomial of the third degree and equated to zero:

$$
a_{1} l-a_{2} l^{2}-a_{3} l^{3}-n=0,
$$

where $a_{1}, a_{2}, a_{3}$ are the coefficients of a polynomial; $l$ is the line length; $n$ is the the number of shunt reactor (SR) groups for charging power of the SHVTL compensation.

To determine the ranges of the resonant length of the line, we vary the parameters of the elements of its substitution circuit within the limits of the existing main electrical networks. Accordingly, we obtain the ranges of changes in the values of the coefficients of the substitution polynomial:

$$
\begin{gathered}
a_{1}=0,084 \div 0,27 ; \\
a_{2}=1,996 \cdot 10^{-4} \div 3,1 \cdot 10^{-4} ; \\
a_{3}=2,055 \cdot 10^{-7} \div 1,55 \cdot 10^{-6} .
\end{gathered}
$$

After determining the ranges of changes in the values of the coefficients of the polynomial (1), we can find the resonance length of the line. Comparison of the results obtained by the expression (1) and by mathematical modeling indicates that extrapolation leads to errors of $3.3 \%$, which is quite acceptable to perform rapid preliminary analysis of the possible appearance of overvoltage at the higher harmonic components for the SHVTL of given length.

Let us investigate, which is the frequency at which are lengths to expect higher harmonic overvoltage when connecting a unloaded AT. We substitute the marginal value of possible parameters of the expressions (2-4) and get graphs of frequency dependence on the length of the line (Fig. 1) for the relevant parameters.

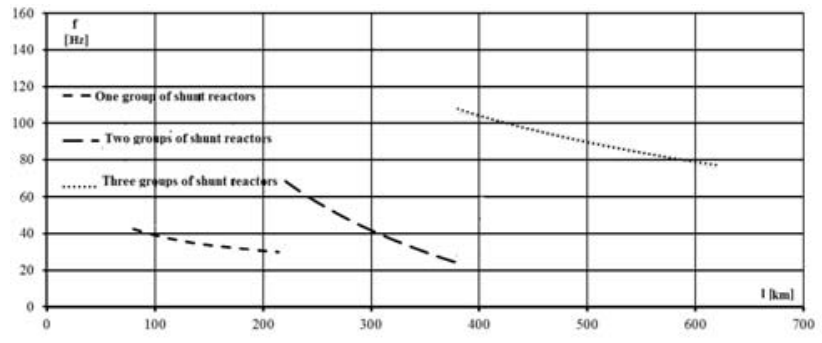

$a$

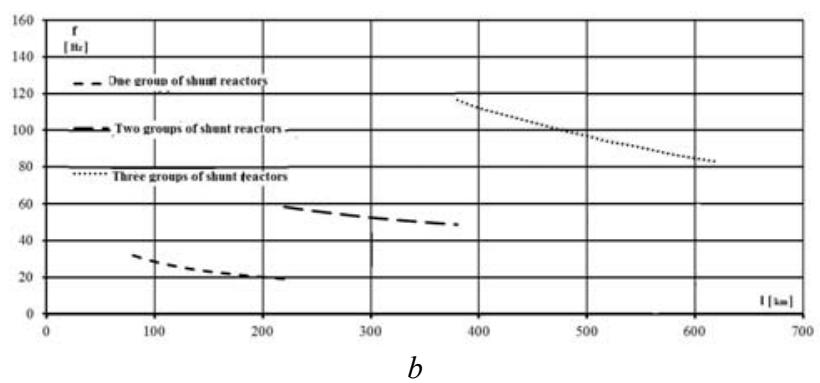

Fig. 1. Resonant length of the SHVTL:

$a$-graphs for lower values of expressions (2-4);

$b$ - graphs for upper values of expressions (2-4) 
The real graphs of the dependencies of the length of the line and frequency for the corresponding number of SRs will lie between the boundary ones (Fig. 1, $a$ and Fig. $1, b)$. One can conclude that the harmonic overvoltage of pairwise multiplicity may arise in the SHVTL when them three groups of SR are installed on them.

Imitation simulation of non-sinusoidal abnormal modes of SHVTL. In the study of harmonic overvoltage, each individual factor can not be considered independent. Changing one parameter may lead to another change, in other words, in this case, there is a correlation between both the parameters of the mode of a particular network and its equipment parameters [5]. The presence of this interdependence does not allow for obtaining clear dependencies that could be used to completely correct the analysis of overvoltage on the second harmonic in the main electrical network and the choice of measures for their prevention, and in this case, as the research experience [3] shows, an effective means for modeling such undefined systems is imitation simulation [5].

In this work, an imitation model for the transmission of SHV was developed for implementation in MATLAB/\&Simulink [10] environment (Fig. 2). Its peculiarity lies in the presence of models of three groups of SR, since it has been shown above that overvoltage in even harmonics arises at the lengths of lines that are required to compensate their charging power, namely, the same number of SR groups [4-6].

The poles of the circuit breakers in the model are considered separately for each of the phases: each pole is modeled by an ideal circuit breaker. This makes it possible to independently change the closing moments of each of the poles during the simulation. The overhead line is modeled by an equivalent substitution circuit with parameters corresponding to the length of the SHVTL. The electric power system is given by a three-phase voltage source and an equivalent reactance.

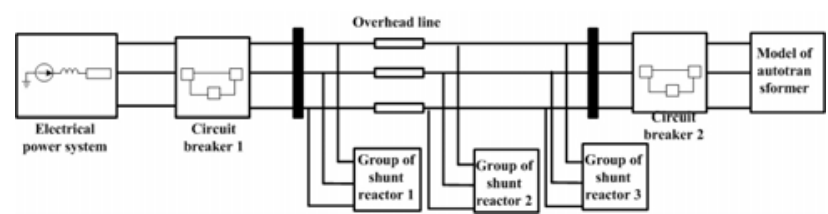

Fig. 2. The imitation model of the SHVTL

Using the model (Fig. 2), in particular, the ranges of angles of switching at which there are dangerous overvoltage are investigated. The research was carried out at a variation of the length of the line from 415 to $525 \mathrm{~km}$. The moment of switching the line to an unloaded AT has changed during the complete period of the sinusoid $\delta \in[0 ; 360]$ in order to detect critical values for the appearance of resonant overvoltage. It is shown that the necessary condition for the occurrence of overvoltage is the coincidence of two factors: the length of the SHVTL and the angle of switching of the poles of the circuit breaker. It should be noted that the length of the SHVTL is one of the determining factors for overvoltage not only in non-sinusoidal, but also in asymmetrical modes [6-9], although the source of distortion of the mode, and the appearance of the corresponding resonant circuits in these cases are different. But the length of the line is determined when designing the track of the line, and the factor of the possibility of occurrence of overvoltage is not taken into account. Thus, for each type of overvoltage, measures for their warning on this SHVTL have to be developed and implemented separately. An event that will be effective for overvoltage in a non-sinusoidal mode will be ineffective in the asymmetric mode and vice versa [6-8]. In modern main electric networks, structural measures, which are connected with the change of the working circuit and preventing the appearance of an abnormal mode, should be used first of all. Also, if necessary, special settings may be used based on the criterion for reducing the resonance overvoltage of devices that have been installed for another purpose.

As studies have shown, overvoltage at switching of an unloaded AT significantly depends on the time point of its switching on. Thus, overvoltage can be limited by using a controlled switching unit configured to close contacts near the zero value of the idle current of the AT, which prevents the emergence of harmonic components. In general, controlled switching is a means of preventing dangerous transients by executing switching on and/or switching off operations at a predetermined time point.

Consider the choice of criteria for switching control on the example of the $\mathrm{SF}_{6}$ circuit breakers widely used in the main networks of the integrated power system of Ukraine at nominal voltage $750 \mathrm{kV}$ - LTB 800E4 of ABB (Asea Brown Boveri Ltd.). The Company completes circuit breakers of its production by controlled switching devices SwitchSync F236. They are intended for the issuance of commands for closing and/or opening the poles of the circuit breaker at the point of the current or voltage sinewave, which is determined by the conditions of elimination of undesirable development of transients at planned switching of sources of reactive energy, shunt reactors, autotransformers, etc. It should be noted that the recommendations for choosing the switching moment for the criterion of the prevention of overvoltage on the higher harmonic components were not available by this time.

In order to study the influence of the switching angles on the development of transients, an appropriate simulation model was developed (Fig. 3), which, unlike that developed in [6], allows us to investigate switching in both normal and abnormal modes.

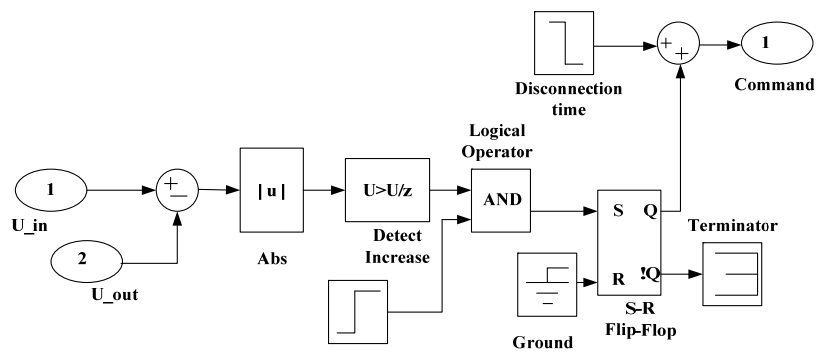

Fig. 3. Imitation model of the controlled switching device Switchsync F236

The block carries out continuous control over the module of current of AT idling. As soon as the curve of the idle current reaches zero value (in the block there are modules where the trend of changing the current value is 
determined), the external command is confirmed and the output signal to the circuit breaker is fed, which, in turn, instantly closes its contacts. In the block of the controlled circuit breaker it is possible to set the moment of closing its poles, usually the closing of the contacts occurs as soon as the difference between the voltage of the source and the voltage at the end of the line reaches the minimum value, after the closing time, which is defined in the block itself.

In order to evaluate the effectiveness of the application of controlled switching to prevent overvoltage on the harmonic components of pairwise multiplicity, consider two SHVTL with the same parameters and characteristics. Each of these two lines is switched by its own circuit breaker. The first line is switched by the circuit breaker with the factory setting, and the second one by the circuit breaker with the selected on the criterion of minimizing harmonic overvoltage of dual multiplicity. The moment of switching of the first line falls into the intervals of the angles $[0 ; 140]$ and $[200 ; 240]$, and the second one - at intervals of angles $[140 ; 215]$ and $[275 ; 355]$. In Fig. 4 graphs of voltages in the first and second SHVTL after the connection of the unloaded AT are presented (amplitude value for nominal working phase voltage of the TL $750 \mathrm{kV}$ is $612 \mathrm{kV}$ ).
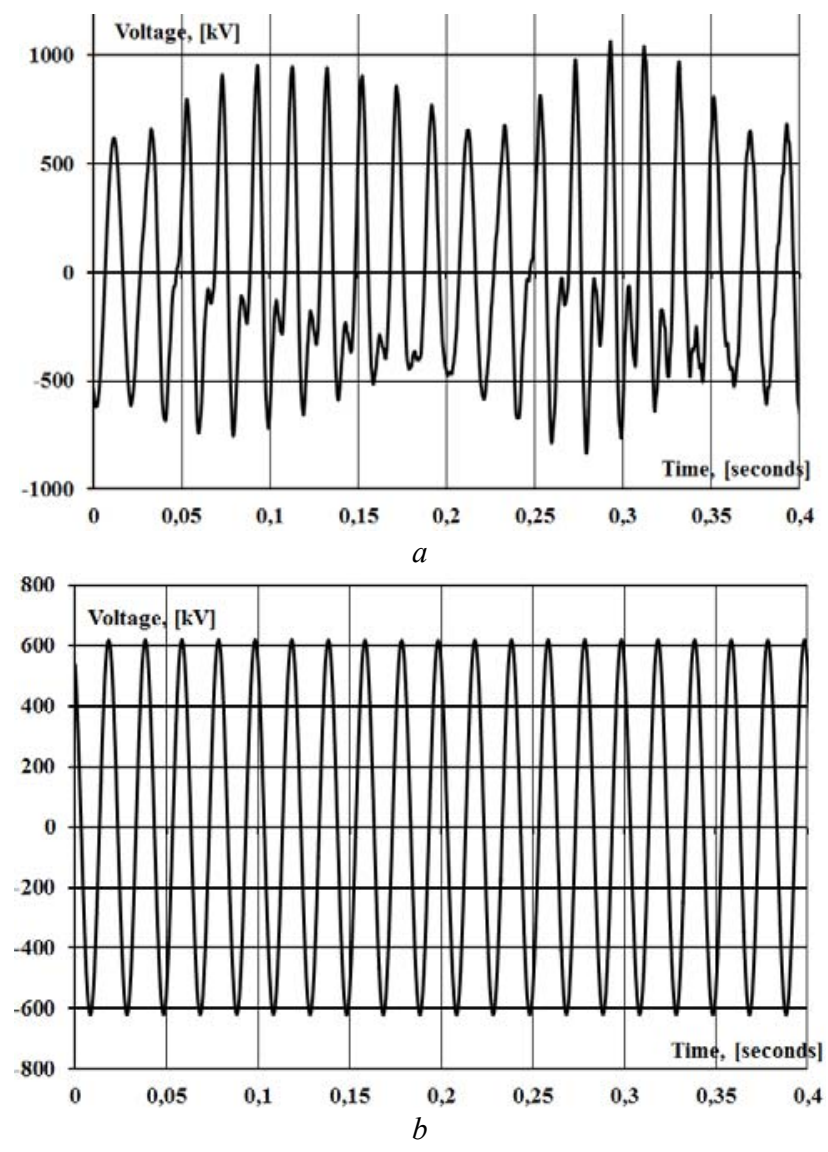

Fig. 4. Voltages of the SHVTL at the device Switchsync F236 settings:

$a$ - standard setting;

$b$ - setting on the non-resonant switching angles

The switching on or switching of commands supplied to the switch are performed in such a way that the contact closure takes place at a given time point in relation to the phase angle. At present, the accuracy of controlled switching is $\pm 2 \mathrm{~ms}$, which can not be considered fully sufficient to minimize the currents when switching off the short circuit, but to prevent the emergence of harmonic components in the current of the unloaded AT, such a spread is not critical. As can be seen, the controlled by the criterion of reducing the harmonic overvoltage switching (Fig. 4,b) significantly limits their multiplicity compared to the standard setting, when the closing moment can fall into the range of the appearance of even harmonic components in the current of the AT.

\section{Conclusions.}

1. A necessary condition for the development of overvoltage in the non-sinusoidal modes of main electrical networks is the emergence of an autoparametric source of nonlinear distortions when the unloaded autotransformer is switched on to the super high voltage transmission line, and the generation of higher harmonic components of even multiplicity characteristic.

2. Resonant adjustment of the electrical circuit of the substitution circuit of the transmission line is a sufficient condition for the overvoltage appearance on the corresponding harmonic component. The defining characteristic of this condition is the length of the transmission line.

3. According to the typical values of parameters of power transmission elements with nominal voltage of 750 $\mathrm{kV}$, an expression was obtained for express analysis of the presence of sufficient conditions for the resonant overvoltage appearance. It is shown that overvoltage on the harmonic components of even multiplicity can be expected if in total three groups of shun reactors are installed in the final substations of the SHVTL.

4. To prevent resonant overvoltage or reduce them to a safe level, it is advisable to use a controlled switching device for $\mathrm{SF}_{6}$ circuit breaker. Intervals of safe switching angles can be determined using developed imitation models of SHVTL.

5. If the switch-on angle of the circuit breaker falls at certain intervals, even if it is adjusted according to another criterion (for example, by the value of the aperiodic component in current), it is possible or completely prevent the occurrence of overvoltage, or to reduce their multiplicity to the levels of effective operation of traditional protective measures.

\section{REFERENCES}

1. Kuznetsov V.G., Tugay Yu.I., Shpolyansky O.G. The using of controlled switching to improve the reliability of the EHV transmission lines. Works of the Institute of Electrodynamics of the National Academy of Sciences of Ukraine, 2012, no.32, pp. 123-128. (Ukr).

2. Naumkin I., Balabin M., Lavrushenko N., Naumkin R. Simulation of the $500 \mathrm{kV}$ SF6 circuit breaker cutoff process during the unsuccessful three-phase autoreclosing. Proceedings of International Conference on Power Systems Transients, Kyoto, Japan, 2011, pp. 5-11.

3. Naumkin I.E. Emergency failures of gas-insulated circuit breakers for switching compensated lines 500-1150 kV. Electricity, 2012, no.10, pp. 22-32. (Rus).

4. de Mattos L.M.N., Mendes A.M.P., Tavares M.C., de Lima Filho J.F. Enhanced analysis of oscillatory undamped 
overvoltages in transformer energization. Electric Power Systems Research, 2016, vol.138, pp. 72-77. doi: 10.1016/j.epsr.2016.03.034.

5. Kuznetsov V.G., Tugay Yu.I., Kuchansky V.V. Investigation of the effect of transposition of the extra high voltage transmission line on abnormal overvoltage. Technical electrodynamics, 2013, no.6, pp. 51-56. (Ukr).

6. De A., Debnath D., Chakrabarti A. A study on the impact of low-amplitude oscillatory switching transients on grid connected EHV transformer windings in a longitudinal power supply system. IEEE Transactions on Power Delivery, 2009, vol.24, no.2, pp. 679-686. doi: 10.1109/tpwrd.2008.2008417.

7. Kuznetsov V.G., Tugay Yu.I., Kuchansky V.V. Overvoltages in single-phase mode. Technical electrodynamics, 2012, no.2, pp. 40-41. (Ukr).

8. Esmeraldo P.C.V., Amon F J., Carvalho F.M.S., Carvalho A.C.C., Morais S.A. Circuit-breaker requirements for alternative configurations of a $500 \mathrm{kV}$ transmission system. IEEE Transactions on Power Delivery, 1999, vol.14, no.1, pp. 169175. doi: 10.1109/61.736710.

9. Morched A., Gustavsen B., Tartibi M. A universal model for accurate calculation of electromagnetic transients on overhead lines and underground cables. IEEE Transactions on Power Delivery, 1999, vol.14, no.3, pp. 1032-1038. doi: 10.1109/61.772350.

How to cite this article:

Kuznetsov V.G., Tugay Yu.I., Kuchanskiy V.V., Lyhovyd Yu.G., Melnichuk V.A. The resonant overvoltage in nonsinusoidal mode of main electric network. Electrical engineering \& electromechanics, 2018, no.2, pp. 69-73. doi: 10.20998/2074-272X.2018.2.12.
10. Ketabi A., Feuillet R. New approach to harmonic overvoltages reduction during transformer energization via controlled switching. 2009 15th International Conference on Intelligent System Applications to Power Systems, Curitiba, Brazil, 2009, pp. 1589-1595. doi: 10.1109/isap.2009.5352837.

Received 14.02.2018

V.G. Kuznetsov ${ }^{1}$, Doctor of Technical Science, Corresponding member of NAS of Ukraine,

Yu.I. Tugay ${ }^{1}$, Doctor of Technical Science,

V.V. Kuchanskiy ${ }^{1}$, Candidate of Technical Science,

Yu.G. Lyhovyd ${ }^{2}$,

V.A. Melnichuk,

${ }^{1}$ The Institute of Electrodynamics of the NAS of Ukraine,

56, prospekt Peremogy, Kiev-57, 03680, Ukraine, phone +380 442230450 ,

e-mail: kuznetsov@ied.org.ua; tugay@ukr.net;

skilldur@ukr.net; yit@ua.fm

${ }^{2}$ UKRENERGO NPC SE,

25, Symona Petliury Str, Kyiv, 01032, Ukraine,

phone +380443662538 ,

e-mail: re_nim_tor@ukr.net 